La observación participante en el Conteo de Población y Vivienda 1995. Una experiencia antropológica

\title{
Dubravka Mindek*
}

Este trabajo gira en torno a la experiencia de una antropóloga que participó como enumeradora en el operativo del Conteo de Población y Vivienda 1995. La autora parte de la descripción de la metodología elaborada por el INEGI para cada etapa del levantamiento de la información en campo, y señala sistemáticamente en qué circunstancias y por qué razones los grupos operativos no respetan las normas prescritas. Asimismo, indica las preguntas que los informantes suelen contestar con dificultad e imprecisión.

Al analizar el proceder y las actitudes de los enumeradores, la autora argumenta que éstos se rigen en campo según las normas informales del grupo-mismo que desde el inicio del operativo tiene una idea precisa sobre el esfuerzo, la cantidad y la calidad del trabajo justo en las circunstancias dadas. En cuanto a los informantes, observa que hay algunos que no entienden las preguntas o bien, que las entienden pero no saben contestar, así como tambièn hay otros que prefieren no contestar correctamente.

Finalmente, su experiencia la hace concluir que la cobertura y la calidad de la información obtenida durante el conteo dependen de losifactores que escapan al control del INEGI, tales como la condición y la disposición de los informantes, y las reglas informales del grupo operativo.

\section{Introducción}

Los científicos sociales utilizamos con frecuencia la información censal que genera el Instituto Nacional de Estadística, Geografia e Informática (INEGI), e igualmente cuestionamos su precisión y confiabilidad, de las cuales dependen en última instancia, la calidad y la cobertura de su levantamiento.

A finales de 1995, mientras estuve elaborando un proyecto de investigación sobre los migrantes de la Mixteca poblana, me enteré de que el Instituto estaba por iniciar el primer Conteo de Población y Vivienda. Consideré que la participación en el operativo podía ser una buena oportunidad para conocer la zona en la que a la larga planeaba realizar la investigación, por lo que solicité de la autoridad competente, previa explicación de mis motivos e in tereses, el trabajo de enumerador.

El enumerador fue la persona responsable de visitar todas las viviendas de una determinada área, con el fin de obtener información

\footnotetext{
* El Colegio de Puebla.
} 
sobre ella y sus ocupantes por medio de una entrevista y un cuestionario. Pensé que el trabajo me facilitaría establecer contacto con los futuros informantes a la vez que permitiría que los habitantes del municipio se acostumbraran a mi presencia entre ellos.

A la postre, no sólo recorrí la mayor parte de un municipio de la Mixteca poblana localidad por localidad, manzana por manzana y casa por casa, sino además tuve una oportunidad única de conocer muy de cerca el proceso del levantamiento de la información censal ${ }^{1}$ en toda su complejidad.

El propósito de este trabajo es describir mi experiencia como miembro de un grupo operativo durante el conteo para señalar, por un lado, algunas circunstancias en las que los enumeradores en el campo no siguen la metodología indicada por el INEGI, y por el otro, la fragilidad y la imprecisión de las respuestas a algunas preguntas que los informantes no entienden, no quieren entender o simplemente no saben responder. Como último fin, espero mostrar que, si bien la información recopilada es de calidad y confiabilidad relativas, ${ }^{2}$ esto debe atribuirse principalmente a los factores sobre los que el Instituto tiene poca o nula influencia, tales como la condición y la disposición del informante, así como la organización informal del grupo operativo y sus reglas implícitas.

\section{Capacitación de los enumeradores}

Para el trabajo de enumeración, el INEGr solicitó la colaboración de personas mayores de edad con escolaridad superior a la secundaria. En la coordinación que se me asignó, la mayoría de los miembros del grupo había terminado la preparatoria, y una que otra persona no la había concluido; además participaron algunos profesionistas. Antes de salir al campo, los enumeradores reclutados tuvimos que asistir a un curso de capacitación con duración

El conteo 1995 consistió en una enumeración o conteo universal, que aplicó un cuestionario corto y a una muestra de la población le presentó una encuesta con un cuestionario amplio. Yo participé únicamente en el conteo, por lo cual en el texto expongo mi experiencia y mis reflexiones en torno de él. $\mathrm{Si}$ al referirme al conteo utilizo el sinónimo censo, es porque consistió "...en enumerar y recabar algunas características de todas las unidades de una población objeto de estudio, con el fin de conocerlas en un momento específico (INEGI, 1995: 2)". El subrayado es mío.

${ }^{2}$ No necesariamente mala. 
de ocho días, impartido por nuestra respectiva coordinadora municipal. ${ }^{3}$

En el curso se trataron detalladamente los aspectos operativos y conceptuales del levantamiento de la información. El aprendizaje fue acumulativo. Diariamente analizamos ciertos temas, mediante la lectura en voz alta del Manual de consulta y apoyo del enumerador, elaborado para la ocasión, o bien por medio de la exposición de alguno de los participantes. Después del primer acercamiento al tema se inició la recapitulación por medio de "juegos educativos", dinámicas de grupo o simplemente mediante el sistema de preguntas y respuestas. La instructora insistió sobre un mismo tema hasta que éste quedó agotado y, al menos aparentemente, bien asimilado. Como instrumento de control del aprendizaje contamos con el Cuadernillo de ejercicios, elaborado, igual que el Manual del enumerador, especialmente para la ocasión. Llenamos de manera individual las partes correspondientes a cada uno de los temas abordados, y después, entre todos, comentamos las respuestas correctas. Cada día la capacitación empezaba con la recapitulación de lo anteriormente aprendido.

En el afán del organizador por llevar a cabo el conteo de la manera más profesional posible, el curso se inició con la presentación de un panorama general sobre el INEGI. Con el fin de evitar las embarazosas situaciones en las que el encuestador no sabría explicar al informante qué es lo que hace, por qué y para quién, nos expusieron la historia del Instituto, su objetivo, su estructura y sus bases legales; de igual manera se habló de los tres censos nacionales ${ }^{4}$ que periódicamente se llevan a cabo en México, y posteriormente se expresaron los motivos, objetivos, metas, metodología y estrategia del conteo de 1995.

Por medio de lecturas y comentarios de la instructora nos enteramos de que debido al carácter y ritmo de las transformaciones socioeconómicas que vive México surgió la necesidad de satisfacer la demanda de información estadística actualizada por medio de un intercenso.

3 Para la enumeración se llevó a cabo una capacitación en "cascada", lo cual quiere decir que un grupo de instructores estatales dio capacitación a los puestos superiores de la estructura operativa, y luego éstos la reprodujeron a los encargados de los puestos que dependían de ellos, y así sucesivamente. Según la estructura organizativa del conteo, el enumerador se ubica en el primer nivel operativo y depende directamente del jefe de enumeradores, el cual a su vez rinde cuentas al coordinador municipal.

${ }^{4}$ El Censo de Población y Vivienda, el Agropecuario y el Económico. 
El INEGI optó por un método de recolección que consiste en una enumeración o conteo universal, que parte de la aplicación de un cuestionario corto, además de una encuesta que se practica sobre una muestra de la población por medio de un cuestionario amplio. Aunque el curso al que asistí fue exclusivamente para los enumeradores, los instructores brindaron la información sobre las principales características de la encuesta, tales como su definición y diferencia del censo, su unidad de análisis, la temática que abarca, la cobertura geográfica, así como la técnica de selección de la muestra.

En cuanto a la metodología que compartirían la enumeración y la encuesta, se insistió en que debía captarse a las personas en la vivien da donde habitan normalmente, siguiendo la tradición de los censos de población y vivienda de un levantamiento de derecho o jure. También se insistió mucho en que el informante adecuado sería el jefe del hogar, su cónyuge, o una persona de 15 años o mayor que residiera en la vivienda y que conociera la información sobre sus ocupantes.

En cuanto a la enumeración propiamente dicha, dedicamos muchas horas del curso a la comprensión de algunos conceptos, tales como vivienda y residente habitual. Para fines del conteo, la vivienda fue definida como un espacio delimitado normalmente por paredes y techos con una entrada independiente donde viven una o más personas, y donde duermen, preparan sus alimentos, comen y se protegen del medio ambiente. La instructora repetía hasta el cansancio la diferencia entre las viviendas particulares que contaríamos, clasificándolas en habitadas, deshabitadas y de uso temporal, y las colectivas. El residente habitual fue definido como toda persona que vive normalmente en la vivienda, es decir, ahí duerme, prepara sus alimentos, come, se protege del medio ambiente y que finalmente, reconoce ese espacio como su lugar de residencia.

Antes de revisar los procedimientos a seguir durante el levantamiento de la información en campo, tuvimos que aprender algunos aspectos de la cartografia censal que sirven para ubicar y referenciar las viviendas contadas dentro del lugar al que pertenecen, es decir, en el espacio geográfico correcto. Durante varios días practicamos la identificación y lectura de los planos de áreas geoestadísticas básicas (AGEB $)^{5}$ que, como equipo, cubriríamos a lo largo de la actividad.

${ }^{5}$ Áreas geográficas que corresponden a una parte de un municipio o localidad. Son áreas de trabajo bien definidas que el equipo operativo va cubriendo según el orden programado. Se identifican mediante una clave. 
Aprendimos que las AGEB se dividen en urbanas y rurales, y que las urbanas comprenden una manzana o grupo de manzanas mientras que las rurales contienen un conjunto de localidades rurales. Supimos que, como enumeradores en localidades urbanas, ${ }^{6}$ contaríamos las casas manzana por manzana, ${ }^{7}$ mientras que en las rurales trabajaríamos sobre segmentos. ${ }^{8}$ Consecuentemente, hicimos una serie de ejercicios de identificación y lectura de los planos de localidades: de su ubicación geográfica, así como la distinción de sus respectivas manzanas y segmentos. Para evitar equivocaciones durante el curso trabajamos directamente sobre el material cartográfico preparado para el conteo.

Puesto que la enumeración consistiría en visitar todas las viviendas particulares para levantar la información sobre ellas y sus residentes habituales, uno de los temas del curso al que se concedió mayor importancia fue el relativo a los instrumentos de captación de la información. Tuvimos que familiarizarnos con el registro de viviendas, un formato que tendría como función enlistarlas una por una, y con un cuadernillo integrado por un conjunto de cuestionarios que serían aplicados en cada vivienda. El registro y el cuadernillo fueron diseñados para ser aplicados por manzana en la zona urbana, y en la zona rural por segmento, lo cual implica que un registro y su respectivo cuadernillo no deben contener información de manzanas o segmentos diferentes. Tuvimos que entender y aprender de memoria los apartados que integraron cada uno de los instrumentos, el tipo de preguntas e indicaciones que contenían, las opciones de respuesta de cada pregunta, así como las reglas generales de llenado y anotación.

Finalmente, el INEGi no sólo contempló la capacitación de los enumeradores en el manejo de cartografía censal e instrumentos de captación, sino también en algunas técnicas de la entrevista. Atendiendo a los fines del conteo, la entrevista fue definida como el diálogo que se establece con el propósito de levantar la información requerida en

\footnotetext{
${ }^{6}$ Es decir, aquellas que tienen una población de 2500 o más habitantes, y que incluyen a todas las cabeceras municipales independientemente del número de habitantes que tengan.

${ }^{7}$ En zonas urbanas la unidad mínima de referenciación de la información y de trabajo operativo para censos es la manzana.

${ }^{8}$ En zonas rurales la unidad mínima de referenciación de la información y de trabajo operativo para censos es el segmento. Dependiendo del tamaño de la localidad rural, ésta equivale a un segmento o se divide en dos o más.
} 
el cuestionario, durante un encuentro de carácter privado y cordial. Ensayamos desde la presentación del enumerador ante el informante, hasta la terminación de la entrevista; pusimos mucho énfasis en tópicos tales como el control de la situación, la neutralidad, el respeto a la secuencia lógica de los temas, la repetición de las preguntas, la confirmación de las respuestas, la utilización de sinónimos o regionalismos, así como la técnica del sondeo para cuando el informante no recordara ciertos datos o tuviera dudas.

Antes de dar por terminado el curso de capacitación, llevamos a cabo medio día de práctica de campo supervisada, realizando entrevistas a la población y anotando sus respuestas en el registro de viviendas y el cuadernillo de cuestionarios. En la tarde del mismo día comentamos nuestras experiencias y los instructores expusieron sus observaciones sobre nuestras actitudes, el manejo de la situación y el cuestionario, así como sobre los errores que cometimos en el llenado.

El último día presentamos un examen escrito. Ya fuera porque todos los asistentes lo aprobaron o porque la mano de obra disponible era justamente la necesaria, la totalidad de los participantes del curso quedó contratada para el operativo.

Integración e interacción del grupo operativo

Hicimos el trabajo de campo mediante equipos integrados por cuatro enumeradores, un validador y el jefe de enumeradores; todos en mi equipo, excepto yo, eran residentes locales. El jefe de enumeradores coordinó y supervisó la labor de los enumeradores en el sentido de que a diario nos asignaba la carga de trabajo, nos llevaba al área correspondiente cuando expresábamos dudas sobre su ubicación, y nos ayudaba en la solución de problemas o dudas que se presentaban en el trabajo de campo. La tarea del validador fue revisar y garantizar la congruencia de la información levantada por los enumeradores y reportar al jefe los problemas encontrados.

Cada equipo tuvo que cubrir un área geográfica determinada. Según la planeación, el nuestro realizaría el conteo en aproximadamente 40 localidades, desde la cabecera municipal hasta una serie de ranchos perdidos en los barrancos o escondidos detrás de los cerros. Empezamos por la cabecera municipal. Nos llevó una semana levantar la información en ella y otras dos en sus diferentes localidades. 
Nuestro centro de acopio fue una improvisada oficina en la presidencia municipal en cuyas paredes estaban pegados un croquis municipal con todas sus localidades y un plano de la cabecera detallando las manzanas enumeradas y los agrupamientos de éstas. El jefe nos indicaba en el mapa las manzanas o los segmentos cuya cobertura había sido programada para ese día y nos repartía el material de apoyo que necesitábamos para cumplir satisfactoriamente con nuestra tarea. Después salíamos a la acción.

Cuando el acceso al área de trabajo era relativamente fácil, ya porque estuviera dentro de la cabecera o porque se ubicara en alguna localidad cercana comunicada por medio de transporte público, empezábamos a trabajar a las siete de la mañana. Cuando el acceso a las localidades era dificil (porque no había transporte público a tal destino, o porque ni siquiera contaban con caminos que permitieran la entrada de algún vehículo), empezábamos a trabajar antes del amanecer. Cooperábamos entre todos para la renta de una camioneta combi, cuyo conductor nos acercaba al lugar de destino lo más que podía. En el punto en que el camino y la topografía ya no permitían el paso del vehículo nos bajábamos de él para proseguir a pie, caminando por senderos y atajos hasta llegar a la meta.

Al terminar la carga de trabajo designada, regresábamos a la oficina; reportábamos aljefe la cantidad de casas que habíamos enumerado así como las que quedaban pendientes debido a que en el momento de nuestra visita no encontramos a sus residentes; entonces intercambiábamos nuestras experiencias. Elijefe de enumeradores y el validador revisaban los registros y los cuadernillos que cada enumerador había entregado, nos señalaban los errores e incongruencias que encontraban en el llenado y, en caso de ser posible, nos hacían corregirlos de inmediato. Finalmente, con un plumón verde tachábamos en el plano el área cubierta ese día, y veíamos con agrado cómo ésta iba creciendo conforme transcurrían los días del operativo. Salíamos de la oficina entre las siete y las nueve de la noche. Al día siguiente repetíamos el procedimiento, empezando por visitar las casas que habían quedado pendientes el día anterior.

Si teníamos dudas sobre la localización en el terreno de las manzanas indicadas, elijefe nos acompañaba y nos ayudaba a ubicarnos y a orientarnos. Se suponía que él conocía bien el terreno, en primer término porque era nativo del lugar, y en segundo, porque anteriormente había asistido a un curso de capacitación para losijefes de los enumeradores. En este curso recorrieron a pie todas las localidades 
de su área de responsabilidad con el fin de actualizar los mapas, levantar los croquis y contar las viviendas a simple vista. ${ }^{9}$ Debido a mi previo desconocimiento de la zona y los lugares, el jefe solía ser mi acompañante o, como él mismo decía, tenía que "ir a dejarme". Esto ocurría invariablemente dentro y fuera de la cabecera municipal; dentro, cuando me tocaba visitar las casas ubicadas a las orillas del pueblo donde el asentamiento era irregular y las manzanas difíciles de delimitar; fuera, cada vez que era necesario llegar a un pueblo o un rancho a pie, por caminos y veredas mal marcados.

Cabe destacar que la obligación de los jefes, o los “j. e.", como fueron apodados en el medio, fue tan sólo orientar y ubicar a los enumeradores; la responsabilidad de aquéllos no era el levantamiento de la información, regla a la que la mayoría se apegó gustosamente. El de mi equipo, sin embargo, nos ayudó a enumerar. ${ }^{10}$ Cuando veía que alguien avanzaba con demasiada lentitud o tenía mucha carga de trabajo, asumía una parte de su labor; hacía las entrevistas anotando los datos con lápiz ${ }^{11}$ en un registro y un cuadernillo cualquiera. Después, en la oficina, el enumerador apoyado copiaba la información en los instrumentos de captación correspondientes; todos los datos referentes a las viviendas y a los residentes habituales de una manzana o, en el caso de las comunidades rurales, de un segmento, tenían que estar presentados conjuntamente. Se borraba lo que el jefe había llenado con lápiz.

La cobertura del área fue cuidadosamente planeada. El número de personas destinadas a censar cada localidad dependía del tamaño de ésta. Algunas veces cada enumerador iba a un lugar de destino diferente, y a veces íbamos dos o tres al mismo. En ocasiones, para un solo día estaba programado el cubrimiento de un pueblo grande y uno o varios ranchos aledaños. Se suponía que cada enumerador levantaría la información en un segmento del pueblo grande y que después alguno de los cuatro iría al rancho. Invariablemente, nuestro jefe asumía esta tarea adicional; se trasladaba con nosotros al pueblo en turno, recorría con cada enumerador un segmento a él asignado y al asegurarse de que todos estábamos bien ubicados emprendía con sus cortos pero rápidos pasos el camino al rancho. De regreso, le pasaba

${ }_{9}^{9}$ El conteo de viviendas a simple vista sirvió como referencia para el conteo de enumeración, y como mecanismo de control del cumplimiento de los enumeradores.

${ }^{10}$ Hacía las entrevistas y llenaba el registro y los cuestionarios.

${ }^{11} \mathrm{La}$ regla fue hacer todo el llenado con el plumón. 
al enumerador suplido el registro y el cuadernillo en los que había captado la información, para que éste llenara las carátulas con sus datos. ${ }^{12}$ Nuestro validador también nos ayudaba en el trabajo de campo cada vez que el jefe o alguno de los enumeradores se lo pedía, aunque tampoco tenía la obligación de hacerlo.

\section{Los enumeradores en el trabajo de campo}

Con frecuencia escuchamos que los encuestadores inventan a sus informantes y las respuestas de éstos. Solemos dudar de los resultados de las investigaciones cuantitativas suponiendo de antemano que la cobertura y la calidad de la información recopilada dejan mucho que desear. Conforme a mi experiencia en el conteo de 1995, el panorama es más alentador.

Para la enumeración, el INEGI desarrolló una metodología (que con esmero nos fue enseñada en la semana de la capacitación que narré) con reglas estrictas y pasos determinados para cada paso del levantamiento de la información en campo. A pesar de que estaban familiarizados con esta metodología y de que contaban con el manual, los enumeradores en ciertas circunstancias violaban las reglas o cambiaban los pasos establecidos para el conteo. Probablemente su proceder tuvo repercusiones negativas en la cobertura y la calidad de la información censal. Sin embargo, considero importante destacar que no se debe confundir su actitud con el boicot o el desinterés por el éxito del operativo. Al contrario, el grupo con el que me tocó colaborar estuvo entusiasmado y comprometido con su trabajo: le interesó cumplir con la tarea y siempre que consideró necesario y posible seguir la metodología prevista para lograrla, lo hizo. Si sus integrantes en ocasiones cambiaban las reglas, e incluso alguna vez llegaban a inventar datos, no cra con el propósito de burlarse del proyecto, de evitar el esfuerzo, o ganar de una manera fácil los honorarios. Fue simplemente porque tenían una idea clara sobre el trabajo diario adecuado en circunstancias dadas, y sobre la intensidad de esfuerzo razonable para la

${ }^{12}$ El registro de viviendas, así como el cuadernillo de cuestionarios tiene una carátula con cuatro secciones que había que llenar debidamente con los siguientes datos: a) identificación geográfica (del área de trabajo de acuerdo con la simbología geoestadística del INEGI); b) nombre de los responsables (enumerador, jefe de enumeradores, validador); c) croquis (de la manzana o segmento en los que se llevó a cabo el conteo); d) resultados de la manzana (segmento). Al enumerador le correspondía llenar las secciones $a, c$ y parte de la $b$. 
cantidad y calidad de la información que debería obtenerse -idea que no necesariamente coincidía con la del INEGr. Me refiero a la contradicción entre la organización formal y la informal del trabajo, conocida y estudiada sobre todo en la labor fabril (Brown, 1982; Lupton, 1963; Hommans, 1972; Mayo, 1977).

Una vez en el área de trabajo asignada, antes de iniciar la enumeración, cada responsable tenía que asegurarse de que se encontraba en el lugar correcto. Para eso estaba obligado a realizar un recorrido de reconocimiento verificando que las calles, los servicios y los demás rasgos culturales o geográficos que encontraba en el camino coincidieran con los de su plano. Sin embargo, los enumeradores no siempre respetaban esa regla. Algunas veces no lo hacían porque la ubicación de su área de trabajo les parecía demasiado clara como para perder el tiempo dando vueltas, y otras porque era muy poco clara y entonces preferían confiar en su intuición y desconfiar del mapa. En ocasiones la consecuencia de tal estrategia fue que el enumerador regresara a la oficina después de unaijornada de trabajo arduo para descubrir que se había metido donde no le correspondía y que, sin embargo, su carga de este día seguía pendiente. Otras veces ocurría que, aunque a grandes rasgos se hubiera ubicado bien el área de trabajo (en zonas rurales), no quedaba del todo clara la línea divisoria entre ésta y la que correspondía a algún compañero, y se intervenía parcialmente en segmentos cuyas casas no eran de nuestra incumbencia. Llegábamos a una casa y aunque nos sorprendíamos al ver la etiqueta de control de cubrimiento pegada, de cualquier manera tocábamos la puerta, para cerciorarnos. Confirmábamos la equivocación cuando algün habitante de la casa nos decía que ya había pasado por allí un encuestador. Si el entrometido llegaba a las casas ubicadas en el área de trabajo de otro compañero antes que éste, se enteraba de su error cuando de regreso a la oficina el otro le reclamaba: “Oye, te metiste en mi segmento. Aquellas tres casas que están al norte del medidor de agua que tú enumeraste están en mi segmento, no en el tuyo". Estos pequeños errores podían provocar confusiones al supervisor $^{13}$ debido a que la información recabada no estaba bien identificada

${ }^{13}$ Los supervisores solían realizar recorridos con el fin de controlar la cobertura de la población y vivienda por cada unidad de análisis. Tomaban el registro de viviendas y el cuadernillo de cuestionarios correspondientes a un segmento o manzana cualquiera y regresaban con ellos al campo. Si en su recorrido encontraban mayor o menor número de casas que las reportadas por el enumerador responsable, le llamaban la atención y le exigían que corrigiera su conteo. 
geográficamente. En lo que se refiere al conteo en sí, no sufría alteración porque el enumerador que llegaba a una casa ya enumerada no la registraba en sus instrumentos de captación, y así la información no se duplicaba.

Problemas más serios surgían cuando los enumeradores omitían el conteo de determinadas casas y sus habitantes, considerando que correspondían al área de trabajo de otro compañero, quien a su vez pensaba lo mismo sobre aquél. Si los implicados se llevaban mal y no tenían mucho sentido de compañerismo, terminaban acusándose mutuamente ante el jefe por el incumplimiento de la tarea. El jefe tomaba una determinación al respecto considerando los siguientes factores: por un lado, la cantidad de casas omitidas y por el otro, la cercanía y el acceso al lugar donde estaban. Si había transporte para el lugar y las casas omitidas eran varias, el jefe obligaba al verdadero responsable a regresar y corregir el error; si las casas omitidas eran pocas y era difícil llegar al pueblo, el jefe le aconsejaba que tan sólo las enlistara en el registro de viviendas y las reportara como deshabitadas. En el caso de que los enumeradores implicados se llevaran bien, quedaban de acuerdo sin siquiera avisarle al jefe; uno de los dos reportaría las casas omitidas como deshabitadas. El que se daba cuenta de la falta ayudaba al responsable informándole cuántas casas eran y cuáles eran sus características. ${ }^{14}$

Tanto para realizar el recorrido de reconocimiento del área como para el de enumeración fueron establecidas ciertas normas. Donde había amanzanamiento se debía empezar por la manzana más próxima al punto noroeste del área de trabajo. Cada manzana debió recorrerse por completo iniciando la labor en la esquina noroeste o en el lugar más próximo a ella, ${ }^{15}$ con dirección hacia el este, hasta llegar al punto de partida. Si la carga diaria abarcaba más de una manzana, al terminar la primera se debía continuar con la que se encontrara en la dirección este para luego descender en forma ondulatoria hacia el oeste, y así sucesivamente hasta recorrer todas las manzanas asignadas. Esta regla implicaba que pasáramos más de una vez por la misma calle (figura 1).

${ }^{14} \mathrm{Al}$ hacer listas de viviendas ahí donde no existían nombres de las calles ni números de las casas, teníamos que anotar algún rasgo de cada casa para poder diferenciarla de otras.

${ }^{15}$ Cuando la configuración de la manzana era irregular. 


\section{FIGURA 1}

\section{Reglas para el recorrido}
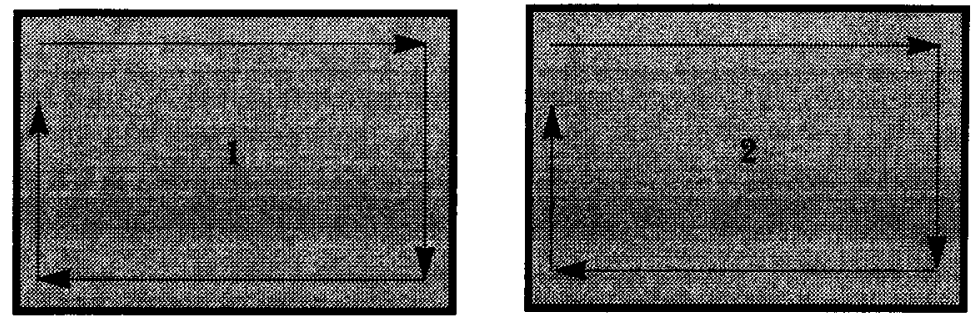

Calle este oeste
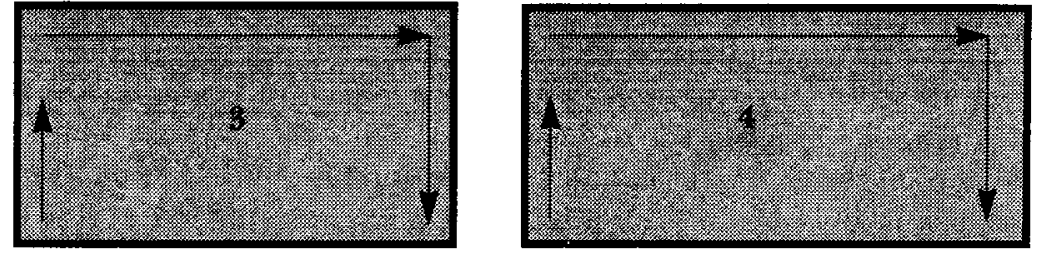

En el área urbana, donde consignábamos las viviendas de cada manzana y sus habitantes en un registro y un cuestionario aparte, no quedaba más que respetar esta regla. En el área rural, donde la información se anotaba por segmentos, y éstos a veces estaban compuestos de varias manzanas, los enumeradores no se atenían estrictamente a la regla del recorrido. En algunas ocasiones, para ahorrarse múltiples caminatas por la misma calle y en otras por querer terminar lo más pron to posible con la parte más pesada del trabajo y poder encuestar las manzanas más alejadas, los enumeradores no respetaron la regla de recorrido de la manzana ni la del orden de ellas (figura 2).

Aunque con tal proceder el enumerador no necesariamente fallaba en lo referente a la cobertura, ${ }^{16} \mathrm{el}$ orden en el que registraba las viviendas confundía a los supervisores y los hacía dudar respecto al adecuado cumplimien to de la tarea, como ocurrió en el último pueblo que enumeramos.

${ }^{16}$ Conforme iba levantando la información el enumerador marcaba en el plano las calles y partes de las manzanas que recorría. 
FIGURA 2

Punto del inicio del recorrido

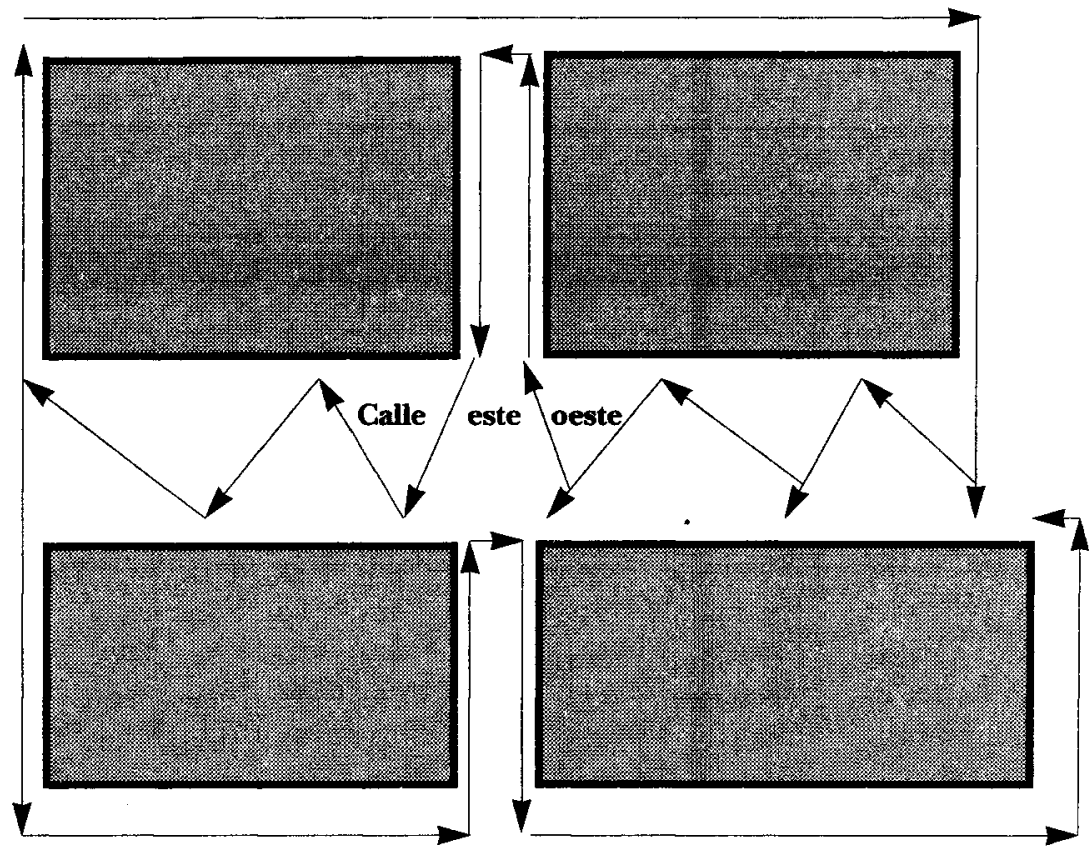

Después de la cabecera, éste fue el pueblo más grande de todo el municipio. Para su cobertura se planearon dosijornadas de trabajo con los cuatro enumeradores. El primer día llegamos al pueblo alrededor de las ocho de la mañana en la camioneta que transporta a los maestros de la primaria local. De ahí nos dirigimos a otro pueblito que estaba atrás de un cerro. Conforme a la planeación, primero contaríamos su población y sus viviendas y de regreso emprenderíamos el censo del pueblo grande. Ese mismo día trataríamos de cubrir la mayor superficie posible y el siguiente trabajaríamos sobre el resto del pueblo. Nos tomó aproximadamente $\mathbf{4 5}$ minutos llegar al pueblito: tuvimos que subir y luego bajar el cerro a pie. Al llegar, nos tardamos aproximadamente otros 45 minutos en recopilar la información. 'Tomamos un refresco, descansamos un cuarto de hora a la sombra de un árbol y emprendimos el retorno. Una vez más subimos y bajamos el cerro, sólo que para entonces el sol ya estaba alto en el cielo y hacía 
un calor sofocante. Regresamos al pueblo grande cansados y sedientos, pero animados porque ya se vislumbraba el fin del operativo. Decidimos seguir trabajando hasta que saliera la última combi de regreso a la cabecera municipal. Con el fin de dejar la menor carga posible, así como las más céntricas manzanas para el último día de trabajo, nos dirigimos a los puntos más alejados de nuestros respectivos segmentos. Desde ahí empezamos a censar calle por calle, cerrando cada vez más el círculo alrededor del centro, sin omitir casas pero igualmente sin respetar los límites ni el orden de las manzanas.

Por azares del destino, al término del operativo las autoridades superiores decidieron llevar a cabo un conteo de control precisamente en aquel pueblo. Al hacer el recorrido de la manera correcta, la información que les fue proporcionada no coincidió con la recopilada por nosotros. Hubo un escándalo. Los supervisores concluyeron que el equipo no había estado en el pueblo y nos acusaron de haber inventado la información. A la larga retiraron sus acusaciones ya que se comprobó que todas las casas fueron enumeradas, aunque según un orden cuya lógica nadie lograba entender. Las etiquetas de control de cobertura y los mismos informantes atestiguaron en nuestro favor; las casas que visitaron los supervisores tenían las etiquetas pegadas y además, en el momento de su visita los informantes preguntaban por la razón de la segunda entrevista, indicando que ya alguien había recabado la información.

Para la entrevista en sí, fue estrictamente acordado que abordaríamos a los informantes en las viviendas donde habitan normalmente. Según la regla, el informante adecuado sería el.jefe o la:jefa del hogar, su cónyuge o un residente habitual de la vivienda, que conociera la información de todos los residentes y que tuviera al menos 15 años de edad; una regla establecida a raíz de la experiencia previa y por lo tanto justificada y respetable. Sin embargo, la complejidad de la vida en la Mixteca poblana la superó. Cabe recordar que el periodo del levantamiento del censo fue del 23 de octubre al 18 de noviembre. En la Mixteca poblana estas fechas coincidieron con la cosecha del cacahuate, y por ello muchas veces no fue posible encontrar a los informantes adecuados en el pueblo, o al menos no fue posible encontrarlos en el solar en el que habitualmente residen. Los adultos estaban en los ejidos recogiendo el fruto, o en las casas de los vecinos, ayudando a limpiar el cacahuate. Siempre que visitábamos casas en cuyos solares había un grupo de gente trabajando, nos topábamos con algún vecino consciente de su deber ciudadano que nos advertía 
que en su casa no encontraríamos a nadie -si es que todavía no habíamos pasado a enumerar dicha vivienda-, y que major de una vez nos contestaba el cuestionario. Con gusto aceptábamos su colaboración. En tales ocasiones el único pequeño inconveniente era la referencia posterior de la casa del informante, por lo cual le pedíamos que la describiera detalladamente. Era necesario identificarla bien para saber si pertenecía al segmento propio o al de algún compañero. Si la casa no pertenecía a nuestro segmento asignado, anotábamos la información obtenida en una libreta y luego se la pasábamos al enumerador a quien le correspondía (antes de abandonar el pueblo hacíamos el intercambio de papelitos). Otra razón por la que era importante identificar y ubicar bien las casas cuya información no se recabó in si$t u$ fue para poder pegarle la etiqueta de control de cobertura en cuanto llegáramos hasta ellas y saberlas enumeradas; de otra manera hubiéramos podido pensar que no teníamos datos sobre estas casas ni sus residentes, en cuyo caso habríamos pedido la ayuda de los vecinos y repetido la información. El resultado del conteo se habría alterado involuntariamente.

¿Por qué los enumeradores hacen este tipo de maniobras? Porque si se apegaran estrictamente a las reglas sobre el lugar y el informante adecuados para la entrevista, no acabarían su labor en meses. La mayoría de las localidades en cuyo conteo participé están muy mal co. municadas con la cabecera municipal, donde el equipo estuvo establecido. Me refiero a pueblos donde no entra el transporte público o lo hace una vez por semana -generalmente los lunes, cuando es día de plaza en Izúcar de Matamoros. Para llegar a ellos hay que contratar un vehículo o viajar con incomodidad en la camioneta que lleva a los maestros de primaria -si es que hay espacio en el vehículo. En ocasiones no queda otra opción que la de ir a pie, porque no hay camino para la circulación de automóviles. Para llegar al área por encuestar es necesario caminar entre media y tres horas por senderos y atajos, quitarse los zapatos, remangar los pantalones y cruzar algún río, atravesar puentes colgantes, subir cerros y luego bajar al fondo de las barrancas, con temperaturas superiores a $30^{\circ} \mathrm{C}$. Bajo estas condiciones y con la limitación del tiempo, no se considera la posibilidad de regresar dos veces al mismo lugar. Los enumeradores recurren a cualquier recurso que les permita levantar la información requerida en el tiempo previsto por la planeación. Aceptan como informante a cualquier persona que quiera y sepa contestarles las preguntas, independientemente de su edad. Si no encuentran al informante adecuado 
dentro de una casa, entrevistan respecto a ella y sus residentes al vecino de al lado, al marchante de la tiendita de la esquina, o incluso al inspector ${ }^{17} \mathrm{del}$ pueblo.

Recuerdo dos ocasiones muy peculiares. Una se refiere al cubrimiento de la localidad con más difícil acceso; para enumerar sus cuarenta casas tuvimos que caminar tres horas de ida y otras tres de vuelta, subir y bajar dos cerros, cruzar varias veces un arroyo, seguir el cauce de un río y además meternos en él. Camino al pueblo, según la planeación, recopilaríamos la información sobre cinco ranchos en los que supuestamente había entre una y cinco casas habitadas. Para cumplir rápida y eficazmente con la tarea, el jefe decidió que todos saldríamos al campo, inclusive el validador. Rentamos una combi que nos llevó a un pueblo ${ }^{18}$ ubicado aproximadamente a $15 \mathrm{~km}$ de distancia de la cabecera municipal, desde el cual emprenderíamos la caminata al otro. Puesto que el pueblo al que llegamos en coche también estaba en nuestra área de cubrimiento, acordamos que dos enumeradores se quedarían allí. Ellos irían adelantando el conteo en dos de sus cuatro segmentos; los dos restantes los cubriríamos un compañero y yo al regresar del otro pueblo.

Antes de dividirse el equipo y de que algunos emprendiéramos la larga caminata, nos presentamos todos con las autoridades locales. Lo hacíamos siempre, en cualquier lugar, para que estuvieran enterados de nuestra presencia en su comunidad y nos brindaran su apoyo si la gente se resistía a colaborar. ${ }^{19}$ En aquella ocasión tuvimos además dos motivos adicionales para entrevistarnos con el presidente auxiliar y su gente: por un lado, queríamos ver si nos podían proporcionar un guía, y por otro, nos proponíamos averiguar qué tanto sabían sobre los ranchitos que teníamos anotados: si todavía estaban habitados o nuestra información ya había caducado. El secretario del presidente, quien resultó ser un excelente conocedor de su pueblo y su gente, nos dijo con precisión qué ranchos ya no existían así como cuántas

${ }^{17}$ Máxima autoridad en localidades pequeñas, ranchos y caseríos de los municipios de la Mixteca poblana.

${ }^{18}$ Uno de tantos que carecían de transporte público a pesar de su numerosa población; por su tamaño era la tercera localidad del municipio, regionalmente bien conocida por su feria anual.

${ }^{19}$ En una comunidad el presidente municipal auxiliar sugirió que no empezáramos a visitar las casas antes de que él anunciara por el altoparlante instalado en la iglesia nuestra presencia y los objetivos de la visita. "La gente aquí es medio difícil y desconfiada", nos dijo. 
casas había en los que permanecían y a qué familias pertenecían. Nos explicó que la gente se concentraba cada día más en el pueblo, que la mayoría tenía una casa en él y que sólo pasaba temporadas en sus ranchos con los animales. Curiosamente, hasta supo decirnos qué familias se encontraban en aquellos momentos en el pueblo y cuáles en sus ranchos. Nos dio nombres de los residentes de todos los ranchos casa por casa, sus edades aproximadas e incluso la condición de alfabetismo de cada quien, en caso de que cuando los visitáramos no encontráramos a nadie, por si anduvieran con sus animales en los cerros o en el río. Anotamos los datos por él proporcionados en nuestra libreta de campo.

En cuanto al guía, las autoridades tenían en mente a una persona a quien habríamos tenido que esperar aproximadamente una hora. Decidimos que no había tiempo para la demora. Teníamos prisa por salir antes de que empezara el calor más intenso. Además queríamos, de ser posible, regresar a la base el mismo día. Como no era recomendable andar por los cerros de noche, tuvimos que apresurarnos. Así que le pedimos al secretario que nos encaminara. Tomamos cada uno un palo, sacamos nuestros mapas y emprendimos la pesada caminata. Por el camino todo el tiempo nos topábamos con la gente que venía del pueblo al que nosotros íbamos. Ellos nos indicaban el rumbo y nos decían el tiempo que faltaba para que llegáramos. De paso los entrevistábamos. A cada persona, o grupo de personas que encontrábamos a lo largo del camino, le explicábamos el motivo de nuestra visita a su comunidad y le pedíamos que nos contestara el cuestionario. En caso de que nos informaran que no encontraríamos a nadie en su casa, le pedíamos que nos la describieran y, de ser posible, la ubicaran en nuestro croquis. Al llegar al pueblo ya habíamos censado a una tercera parte de su población. Para nuestros fines dividimos las cuarenta casas restantes en cuatro segmentos ${ }^{20}$ y los cuatro enumeradores empezamos a levantar la información. Debido a que $20 \%$ de las viviendas estaba desocupado, porque sus dueños trabajaban en Estados Unidos, terminamos el comeo en la comunidad en media hora. Durante el recorrido y con la ayuda de los vecinos presentes, identificamos las casas cuyos residentes habíamos censado en el cerro y pegamos las etiquetas correspondientes. Fue importante identificarlas para que no omitiéramos ninguna pensando que ya teníamos registrada la

\footnotetext{
${ }^{20}$ Conforme a la planeación el pueblo estuvo dividido en dos.
} 
información correspondiente, así como para evitar duplicarla. Por suerte el pueblo fue suficientemente pequeño como para no confundirnos y su gente, tal vez porque veía pocos visitantes foráneos en su comunidad, muy comunicativa. Se adelantaban a nuestras preguntas avisándonos que ahí más adelante estaba el solar de su hija o cuñada que se había ido y que no encontraríamos a nadie en casa: "seguro se los encontraron en el cerro. Una pareja con un niño y con ellos iba una señora mayor en el burro. Es mi vecina, su casa es esta que tiene el granero".

Originalmente nuestrojefe había pensado dejarme con otro enumerador en el pueblo mientras él y el validador se iban a buscar los ranchitos dispersos a lo largo del río. Puesto que tanto mi compañero como yo expresamos serias dudas sobre nuestra capacidad para regresarnos sin su orientación, cambió de estrategia. Por esa razón nos ayudaron en el pueblo y después, por el camino de regreso fuimos todos :juntos a buscar los ranchos. Al llegar a cada uno de éstos, empezábamos a gritar "buenos días". Si había quién nos contestara, le hacíamos la entrevista. Comparábamos los datos que nos daba el informante con los ofrecidos por el secretario, corregíamos los que no estaban correctos y los pasábamos al registro y su respectivo cuadernillo. Ahí donde no encontrábamos a la gente, considerábamos correctos los datos del secretario y como tales los registrábamos. No cabía en nuestros proyectos la más remota posibilidad de regresar. Con el hecho de habernos esforzado por llegar a estos lugares, el equipo sentía que había cumplido. Todos pensamos lo mismo: que otros en nuestro lugar probablemente ni siquiera hubieran ido a buscarlos.

Hasta donde tengo conocimiento, sólo en una ocasión el equipo no visitó el lugar indicado e inventó parcialmente los datos. Se trataba de un rancho de nueve casas, según determinó el conteo previo hecho a simple vista. Como en el caso anterior, para ese día se programó terminar el conteo en un pueblo grande y varias localidades pequeñas.

Llegamos al pueblo grande en una camioneta -esta vez sí hubo transporte público. Hicimos el recorrido de reconocimiento con el jefe por los segmentos asignados a cada enumerador. A sugerencia de él, antes de iniciar la labor ahí mismo nos dirigimos cada uno a un rancho; éstos están situados sobre las colinas que rodean al pueblo y se encuentran alejados de éste aproximadamente a 45 minutos de caminata. El jefe acompañó al enumerador que tenía que ir más lejos. Nos contaron después que llevaban caminando aproximadamente 15 
minutos cuando se encontraron con una pareja que llevaba a un niño montado en un burro. Como venían de la dirección del rancho, los detuvieron y preguntaron si eran de ahí. Al contestar afirmativamente, el jefe les preguntó por el nombre del inspector del lugar, y si sabían si se encontraba en su domicilio. Casualmente, el señor que detuvieron era el mismo inspector; aprovechando su buena volun tad consiguieron los nombres de todos los habitantes del rancho, casa por casa. $\mathrm{El}$ inspector les informó que cinco de ellas estaban habitadas y cuatro deshabitadas. El jefe había visitado el lugar en una ocasión anterior y sabía que las casas no tenían agua potable, luz, ni drenaje. Decidieron no proseguir. Contaban con la mayor parte de la información necesaria y además, como el inspector no estaría presente, supusieron que la gente se mostraría hostil y desconfiada. "Lo único" que quedó por inventar fueron las edades y la condición de alfabetismo de los residentes, datos que, pensaron, de cualquier manera los informantes desconocen y por lo tanto en su mayoría inventan. Lo curioso de este incidente es que al regresar a la oficina y revisar el cuadernillo de cuestionarios el jefe se disgustó con el enumerador porque había escrito de forma incorrecta algunos nombres; le exigió que los corrigiera.

Por lo demás, siempre existió la sospecha de que un miembro del equipo hacía trampa, pero nunca llegamos a comprobarlo. Era un joven que siempre terminaba primero sus cargas diarias, era el más productivo y nunca, durante todo el operativo, dejó ninguna casa pendiente para el siguiente día -ni siquiera en la cabecera municipal, donde a los demás nos ocurría a diario. Cuando en algún momento le expresamos nuestras dudas sobre su eficiencia, nos contestó bromeando que a él la gente, cuando se ausentaba, ¡le dejaba en la puerta los papelitos con todas las preguntas del cuestionario ya contestadas!

Por las mismas razones que llevaron a los enumeradores a no respetar la regla de abordar al informante en la casa en que residía, tampoco respetaron la referente al límite de edades del informante adecuado. Si en las casas visitadas encontraban solamente a alguien menor de 15 años y éste sabía contestar las preguntas del cuestionario, no vacilaban en aplicárselo. Cabe destacar que en muchas ocasiones los niños en edad escolar resultaron ser mejores conocedores de las edades y las escolaridades de los residentes de su casa que algún adulto, quien incluso los llamaba y consultaba cuando tenía dudas para responder a las preguntas del cuestionario. 
Al término de la entrevista el enumerador tenía que pedir permiso para pegar la etiqueta del conteo en un lugar visible de la casa, como instrumento de control de cubrimiento del área. La función de las etiquetas es ayudar al enumerador a ubicar casas pendientes, así como a los supervisores a controlar el cubrimiento y/o encontrar al enumerador en el campo. En torno del manejo de las etiquetas, los enumeradores cuentan muchas anécdotas. En lo personal, constantemente se me olvidaba pegarlas; en cambio otro enumerador las pegaba hasta en las casas deshabitadas y abandonadas.

En ocasion es a propósito no las pegábamos, como parte del acuerdo que hacíamos con los informantes. Procedíamos así cuando las señoras se negaban a contestar las preguntas del cuestionario alegando que sus esposos no las autorizaban para hacerlo. Trataban de convencernos de que mejor regresáramos cuando ellos estuvieran presentes. Justificaban su actitud explicándonos que los esposos se enojarían con ellas si nos proporcionaban los datos en su ausencia. Entonces empezaba la labor de convencimiento por nuestra parte. Solíamos argumentar que seguramente el señor no se enojaría, puesto que las preguntas no tocaban el tema de la economía ni el de las propiedades. Intentábamos que se apiadaran de nosotros alegando que todos los demás nos habían proporcionado los datos, que con el calor infernal que hacía y lo difícil que era llegar al pueblo -y a otros tantos que todavía teníamos que recorrer-, nos resultaría muy complicado regresar. Recurríamos a la ley alegando que la información era confidencial y que era deber de todos los ciudadanos proporcionarla. Si ninguno de nuestros argumentos surtía el efecto deseado, "amenazábamos"; advertíamos que si no nos contestaban el cuestionario las autoridades municipales les mandarían un citatorio y los obligarían a contestarlo de cualquier forma, pero además tendrían que hacer el viaje a la coordinación municipal y perder tiempo, con lo cual el señor sí se enojaría, y con mucha razón. Después de pintar ese panorama bastante negro, optábamos por convenir con las señoras que ellas nos proporcionarían la información necesaria y, para que el esposo no se enterara, nosotros no pegaríamos la etiqueta. Hacíamos el mismo trato cuando queríamos convencer a los vecinos de que nos contestaran los cuestionarios sobre los residentes de las casas que en momentos de nuestra visita estaban solas. La gente generalmente vacilaba, porque no estaba segura de cómo tomarían su intromisión los de la casa en cuestión: “¿Qué tal si se enojan al enterarse que yo le di sus 
datos, joven?", nos preguntaban. Para tranquilizar al informante indebido y agilizar nuestro trabajo, recurríamos al santo remedio: "No se preocupe señor, su vecino ni se va a enterar porque no le voy a pegar la etiqueta".

Los residentes habituales de cada vivienda se enlistaban con un número consecutivo. Los enumeradores tenían que circular el número correspondiente a la persona que les había concedido la entrevista. Como no podían admitir que habían entrevistado al vecino o a un menor de 15 años de edad, circulaban arbitrariamente el número correspondiente a un hombre o una mujer mayor de edad.

\section{Preguntas difíciles, respuestas débiles}

La primera pregunta con la que tropezaron los enumeradores fue la referente al número de viviendas que hay en un solar o un predio. Como ya señalé en el apartado sobre los contenidos del curso de capacitación, la unidad de análisis del conteo fue la vivienda o la casa, definida clara y distintamente del hogar o la familia. Solamente en el caso de que dentro de un solar hubiera habido varias construcciones o cuartos separados y con entradas independientes, una casa equivaldría a un hogar. El Manual del enumerador (p. 63) dice al respecto:

Cuando dentro de un predio existan construcciones separadas, aplique textualmente la pregunta sobre el número de viviendas. Verifique en primer lugar si las construcciones tienen acceso independiente desde el patio o pasillo y pregunte si sus ocupantes comparten el gasto para la comida, si es así, considérela una vivienda. Cuando las construcciones tengan acceso independiente, pero los ocupantes de una u otra construcción no compartan el gasto para la comida, considérelas como viviendas distintas.

Los jóvenes contratados para el operativo carecían de conocimientos antropológicos y sociodemográficos sobre las formas de la organización social. En situaciones como la descrita, y también cuando los informantes no entendían la pregunta sobre el número de viviendas, optaban por utilizar como sinónimo el término familia. Los instructores del INEGI se enteraron de esta confusión de conceptos una semana después de haber iniciado el operativo, en la jornada de la re- 
orien tación ${ }^{21}$ y pidieron categóricamente a los enumeradores que dejaran de hacerlo. Sin embargo, quién sabe cuántas familias y hogares habrían sido contados como viviendas hasta entonces.

Los cuestionarios que aplicamos en cada casa contenían dos secciones, una sobre las características de la vivienda y otra sobre las características de los residentes habituales. En la primera registrábamos información acerca de los servicios básicos con que contaba la vivien$\mathrm{da}$, tales como agua entubada, drenaje y electricidad.

En cuanto al agua, no hubo mayores problemas para captar la información, salvo que la gente de la región entiende mejor el término agua potable que agua entubada. Tal vez valga la pena mencionar la confusión que en ocasiones mostraban los informantes respecto a la ubicación de la llave. La pregunta " $¿$ los ocupantes de esta vivienda disponen de agua entubada?", está diseñada para leérsela textualmente al informante junto con las opciones de respuesta que fueron: ¿dentro de la vivienda?; ¿fuera de la vivienda pero dentro del terreno?; ¿de llave pública o hidrante?; ¿no dispone de agua entubada? A veces los informantes al escuchar la primera opción contestaban afirmativamente sin esperar que el enumerador leyera las demás. Su respuesta corresponde a cierta lógica y tiene que ver con el hecho de que, al salir a la calle a contestar nuestras preguntas, la llave quedaba adentro, en el patio que está atrás de la casa.

En cuanto al drenaje, lamentablemente hay que decir que ni los enumeradores, ni los informantes, ni tampoco los instructores, entendieron claramente qué es, qué no es y en qué se diferencia de la fosa séptica. El día de la reorientación discutimos mucho sobre cómo definirlo, ${ }^{22}$ incluso fue hecha una llamada a la sede de INEG en Aguascalientes con el fin de que los diseñadores del cuestionario tomaran una determinación al respecto. Me imagino que ellos también se vieron en apuros y tuvieron que convocar a una reunión para discutir el asunto, ya que la respuesta llegó tres horas después y tampoco satisfizo a todos.

La sección sobre las características de los residentes habituales de la vivienda tuvo como objeto conocer el número de éstos

${ }^{21}$ A la semana de haber iniciado el trabajo de campo, todos los enumeradores y susjefes fueron llamados a la coordinación municipal para que comentaran públicamente los problemas con los que se encontraban en campo y tratar de resolverlos de común acuerdo y con la asesoría de las autoridades competentes del INEGr que para esa ocasión llegaron de la sede del Instituto en Aguascalientes.

${ }^{22}$ A pesar de que ya en el curso lo habíamos definido, en campo surgieron muchas dudas al respecto. 
asî como su sexo, edad, alfabetismo y la condición de habla indígena.

Empezábamos por enlistar a las personas que residían habitualmente en la vivienda. Con frecuencia los informantes omitían a los niños pequeños y ancianos, a pesar de que el enumerador les enfatizara que ellos también contaban. Era necesario que fuéramos hábiles y buenos observadores y que indagáramos por cada "sospechoso" que veíamos entrar o salir de la casa: "¿Y la abuelita, quién es? ¿cómo se lla$m a$ ? ¿vive aqui? ¿ya me la anotó? ¿y este niño?" Era necesario también que nos armáramos de paciencia para no perder la compostura cuando los informantes nos preguntaban por enésima vez, con una cara de sorpresa, como si no hubieran oído nuestra advertencia de hace un minuto: “¿A poco también el tiernito cuenta?" Igualmente se requería cierta habilidad para que el enumerador detectara cuándo el informante le estaba reportando como residente habitual a alguien que, según las normas del INEGI, no lo era. En la Mixteca poblana la mayoría de las familias tiene entre uno y varios miembros trabajando en Estados Unidos; sin embargo, sus padres y esposas suelen contarlos como residentes habituales de sus casas. Cuando nos dimos cuenta de esto, no sólo enfatizamos que no olvidaran a los niños y a los ancianos, sino también que no contaran a los miembros de su familia que se encontraban viviendo en Estados Unidos; sin embargo, nunca sabremos cuántas veces hasta entonces y cuántas después, a pesar de nuestra advertencia, habíamos registrado un incorrecto número de residentes habituales de la vivienda.

Indudablemente, el dato menos preciso y confiable es el referente a las edades de la población. La gente en su mayoría desconoce su propia edad, la de sus esposos y con frecuencia también la de sus hijos. Ante la insistencia ${ }^{23}$ del enumerador, el informante empezaba a inventar, muchas veces sin ninguna lógica. Por ejemplo, le dicen a uno: "Póngale a mi esposa 40 y a mi hijo 30 ".

Para hacer el registro de las edades de los habitantes de una casa, el enumerador leía textualmente la pregunta “¿Cuántos años cumplidos tiene?"24 La gente invariablemente no oía la palabra "cumplidos".

${ }^{23} \mathrm{El}$ Manual del enumerador (p. 110) dice que si el informante contesta que no sabe la edad de las personas que residen con él en la misma casa, hay que apoyarlo para que proporcione una edad aproximada debido a que la respuesta a esta pregunta es indispensable.

${ }^{24}$ Se menciona el nombre de cada persona enlistada. 
Cuando el informante sí sabía la edad de sus corresidentes, sobre todo la de los hijos, casi siempre informaba los años que la persona iba a cumplir y no los cumplidos: "entró a los diez", o "anda por los quince".

En cuanto al alfabetismo, fue acordado que una persona sabe leer y escribir cuando puede leer y escribir un recado. En la Mixteca poblana la respuesta más frecuente a esta pregunta fue "poquito". ¿Cuánto es poquito? Al indagar, por lo general nos dábamos cuenta de que los que escriben "poquito" en verdad sólo sabían escribir su nombre. Esto, según las reglas del INEGr no fue suficiente para declararlos alfabetos. Por lo demás, siempre dudé respecto a las declaraciones de los padres analfabetos sobre la capacidad de lectura y escritura de sus hijos. Si un niño que va en tercero de primaria supuestamente no sabe leer, ¿dónde está el error? ¿en la capacidad de juicio del informante, la capacidad de aprendizaje del niño o la calidad del maestro?

En lo referente a si hablan alguna lengua indígena, me llamó la atención que la gente contestara "no, nosotros aqui nomás mexicano" no como sinónimo del náhuatl sino refiriéndose al español. Asimismo, algunos informantes omitían escuchar la palabra "indígena" y se apresuraban a destacar que alguno de los residentes de su casa hablaba inglés.

\section{Nota final}

El cuestionario para el conteo fue breve y aparentemente sencillo y el INEG hizo lo posible por lograr la máxima cobertura de población y vivienda, así como por obtener información de óptima calidad. Los expertos en la materia pensaron en una amplia gama de posibles contratiempos y errores así como en sus soluciones y correcciones. Sin embargo, como sucede siempre que se trabaja con los humanos, fue imposible prever y prevenirlo todo. En cuanto a los enumeradores, desde el inicio del operativo se rigieron según las reglas del grupo informal, las cuales en algunas ocasiones coincidian con las reglas formales prescritas por el INEGI, pero en otras no. En cuanto a los informantes, algunas veces por desconfianza y otras por desconocimiento, proporcionaban información incorrecta. Al menos simbóliçamente, los enumeradores y los informantes comparten con el INEGI la responsabilidad por los resultados del proyecto. 
Por otra parte, una vez leí que varios sicólogos entraron como pacientes en un hospital siquiátrico con el fin de hacer una investigación y que después de algún tiempo perdieron la noción de la verdadera razón por la cual estaban ahí. Cuando colaboré en el conteo me pasó algo parecido: muy pronto dejé de ser antropóloga y empecé a sentirme y a actuar como enumeradora. El equipo me ayudó, ya que no hubo privilegios, consideraciones ni disimulos ante mí, a pesar de que todos conocían mi particular situación. Así, igual que ellos, más de una vez llegué a perder la compostura ante los desconfiados informantes temerosos de los impuestos, olvidándome de la imagen del entrevistador comprensivo y empático, oyente no amenazador. Igual que ellos, llegué a sentir el cansancio y el aburrimiento por el diario repetir de la tediosa tarea; igual que ellos veía con alegría cómo aumentaba la superficie pintada de verde en nuestro mapa de control de cobertura. Estuve de acuerdo cuando en la última semana del operativo el grupo empezó a reportar menos trabajo del que realmente hacía, con el fin de evitar que nos mandaran como apoyo a algún grupo retrasado. ${ }^{25}$

Al regresar a mi casa después de un mes de ausencia, me sorprendió encontrar pegada en mi puerta la etiqueta del Conteo 1995. Me sorprendí aún más cuando bajo la puerta encontré la siguiente nota: "Su vecina del 224 me dio la razón de usted. Atentamente, fulano de tal."

\section{Bibliografia}

Brown, J. A. C. (1982), La psicología social en la industria, México, Fondo de Cultura Económica.

Hommans, George (1972), El grupo humano, Buenos Aires, Eudeba. INEGI (1995), Manual del enumerador, Aguascalientes.

Lupton, T. (1963), On the Shop Floor. Two Studies on Workshop Organization and Output, Oxford, Pergamon Press.

Mayo, Elton (1977), Problemas sociales de una civilizacion industrial, Buenos Aires, Nueva Visión.

${ }^{25}$ En una de las reuniones realizadas en la coordinación municipal fue decidido que los equipos que terminaran su trabajo antes del tiempo previsto irían a ayudar a los retrasados, lo que según mis conocimientos todos los grupos operativos trataron de evitar. La manera como lo hicieron coincide otra vez con el comportamiento de los grupos informales en la industria. 
